\title{
The Study of the Component of Sensorineural Hearing Loss in Cases of Chronic Suppurative otitis Media
}

\author{
Dr.Reena Vare ${ }^{1}$, Dr.Anil Vare ${ }^{2}$, Dr.Rajendra Bohra ${ }^{3}$, Dr.Ashfaq Ansari ${ }^{4}$, \\ Dr. Deepinder Dhillon ${ }^{5}$, Dr. Shaima Ahmed ${ }^{6}$ \\ ${ }^{1}$ Professor, Department of ENT, MGM Medical College, Aurangabad, Maharashtra, India \\ ${ }^{2}$ Associate professor, Department of Pathology, MGM Medical College, Aurangabad, Maharashtra, India. \\ ${ }^{3}$ Professor, Department of ENT, MGM Medical College, Aurangabad, Maharashtra, India. \\ ${ }^{4}$ Associate professor, Department of ENT, MGM Medical College, Aurangabad, Maharashtra, India. \\ ${ }^{5}$ Resident, Department of ENT, MGM Medical College, Aurangabad, Maharashtra, India \\ ${ }^{6}$ Department of ENT, MGM Medical College, Aurangabad, Maharashtra, India
}

\begin{abstract}
:
Aim: To study the occurrence of sensorineural hearing loss in safe and unsafe CSOM. Methods: The study was carried out on 100 patients of CSOM at primary level health centre.Result:15\% of patients had mixed component of hearing loss(SN componenet).
\end{abstract}

Keywords: Sensorineural hearing loss, chronic supprative otitis media(CSOM), round window.

\section{Introduction}

Chronic middle ear disease especially chronic supprative otoitis media (CSOM) is a major public health problem in developing countries.It usually leads to significant hearing loss, sensorineural hearing loss is one of them. Chronic suppurative otitis media is a stage of the ear disease in which there is chronic infection of the middle ear cleft i.e. Eustachian tube, middle ear and mastoid and in which a non-intact tympanic membrane(eg. Perforation) and discharge are present.The role of the round window membrane in the determination of sensorineural hearing loss in cases of chronic suppurative otitis media has been studied by many scientists. Round window is a semipermeable membrane, which allows some toxic materials to pass and cause biochemical changes in perilymph and endolymph causing destruction of the organ of corti.

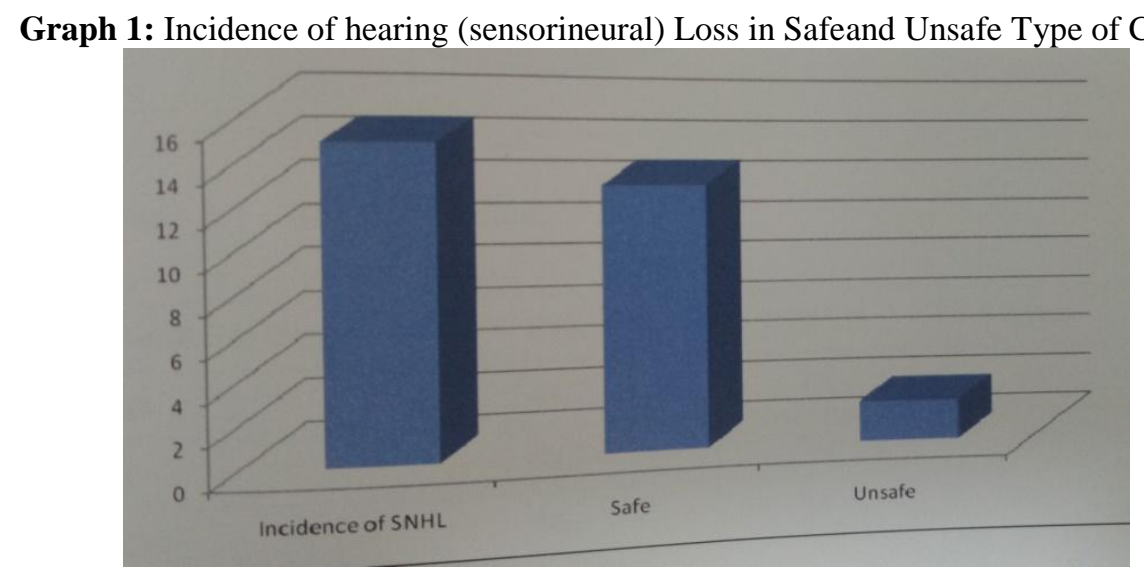

\section{Material And Methods}

100 patients were selected from ENT outpatient department of Mahatma Gandhi Medical College and Hospital., Aurangabad. Patients were between the age of 10-40 years with complains of unilateral ear discharge, deafness more than 6 weeks, with overall clinical picture suggestive of CSOM.Exclusion criteria consisted of patients with history of longterm intake of systemic ototoxic drugs, ear surgery, head injury and patient above the age of 40 years as they may gradually develop presbyacusis. Methodology consisted of complete examination of ear canal, tympanic membrane, mastoid, and inner ear.The tuning fork tests, pure tone audiograms to assess the type and extent of any hearing impairment were carried out. 


\section{Discussion}

The present study was conducted from May 2011 to december2012, during which 100 cases between the age of 10-40 years were studied.They were analyzed according to age, type of CSOM, and the type of hearing loss and the relation between the duration of disease and hearing loss.In our study we observed that out of 100 cases between the age 10-40 years, 15 cases (15\%) had mixed type of hearing loss, 85 cases $(85 \%)$ had CHL.We studied both hearing loss in the types of CSOM 15\% patients had unsafe ears and only 2 of the 15 patients with unsafe ear had mixed component of hearing $\operatorname{loss}(13.66 \%)$. The remaining 13 patients of unsafe CSOM had conductive type of hearing loss. It was also seen that $85 \%$ of the cases that were studied had a safe type of CSOM and 13 patients had show the mixed component of hearing loss(15.29\%).

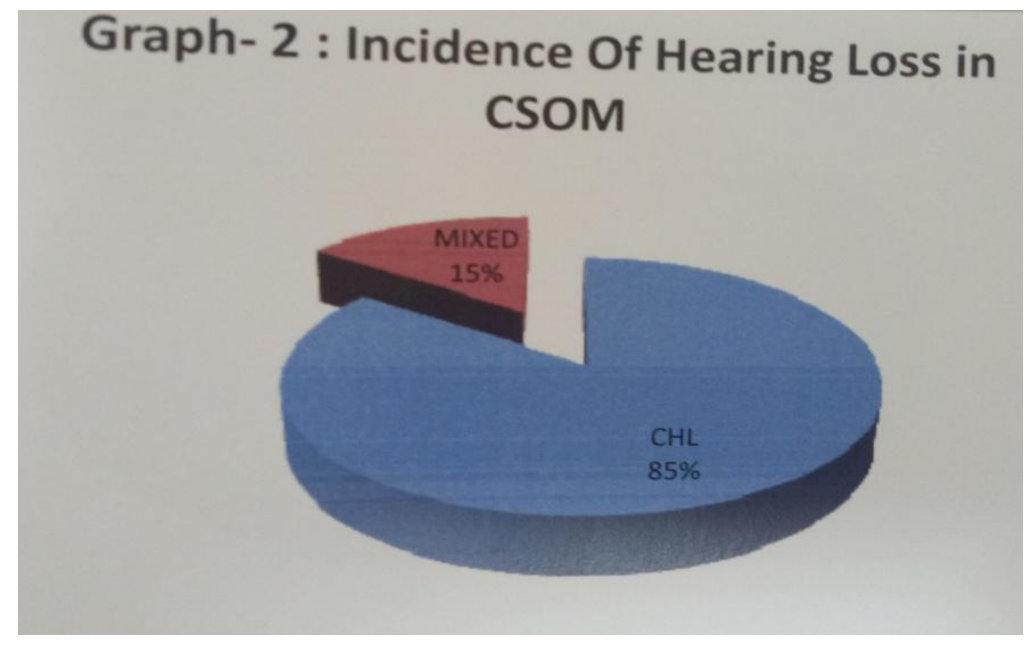

\section{Conclusion}

This study showed the incidence of sensorineural hearing loss in patients of CSOM between the ages of 10-40 years i.e 100 patients. The incidence was $15 \%$ of the patients had mixed component of hearing loss. And it was seen that $85 \%$ of the patients were having safe type of CSOM and they showed 13 patients(15.29\%) had mixed componr=ent of hearing loss(SN component). A total of 15 patientss out of 100 patients suffering from CSOM were unsafe type and 2 patients (13.66\%) has shown presence of mixed hearing loss(SN component).

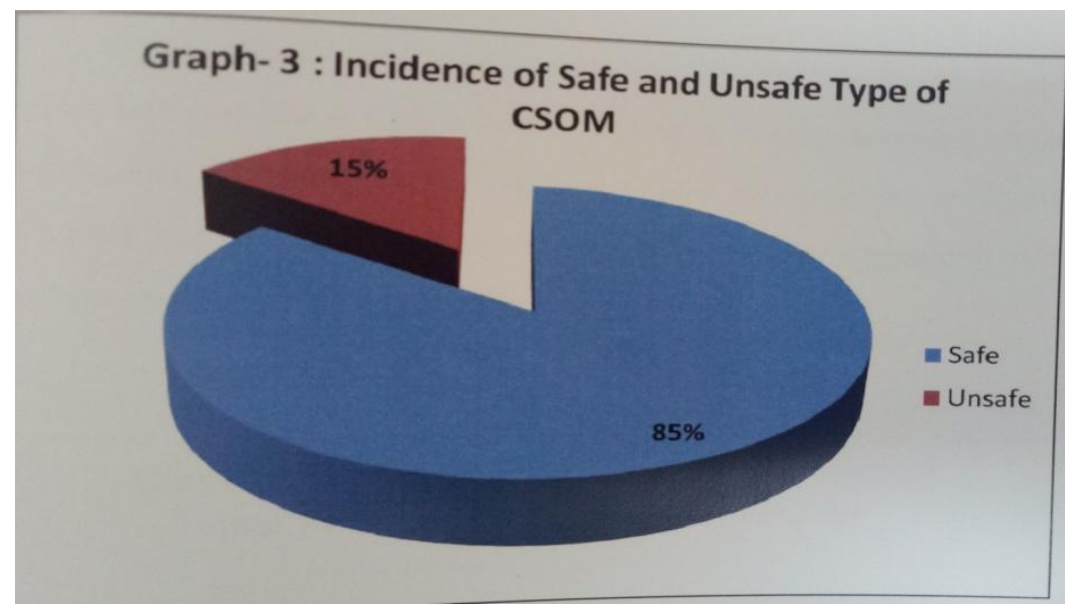

\section{References}

[1]. Mann S B , Sharma C(1998): Incidence of hearing impairment among the rural and urban school going children. Indian journal of Peadiatrics 65(1): 141-145.

[2]. Goycoola MV, Papperalla MM, Jusatin SK, Carepenter A (1980): Oval and round window changes in otitis media. Potential pathway between middle and inner laryngoscope. 90:13 87-139.

[3]. Papperalla MM , Morizono T, Le CT et al (1984) : Sensorineural hearing loss in otitis media. Ann Otolrhinolaryngol 93:623-629.

[4]. Sahini RS, Papperalla MM, Schachern PA, Goycoolea MV, Le CT (1987_: thickness of round window in different forms of otitis media. Arch Otolaryngol Head and Neck surgery 113: 630-634.

[5]. Walby Ap, Barrera, S Chukneckt HF(1983): Cochlear pathology in CSOM. Am Otol Rhinolaryngol (Suppl) 92(103) : 13-15. 